\title{
Numerical assessment of reinforced concrete beams strengthened with CFRP sheets under impact loading
}

\author{
Mohamed Emara, Nada Elkomy, Hilal Hassan \\ Structural Engineering Dept., Faculty of Engineering, Zagarig University, Zagarig, 44519, Egypt \\ mremara@eng.zu.edu.eg, bttp:/ / orcid.org/0000-0003-4936-5257 \\ nadaelkomy16@gmail.com \\ babdelkader@zu.edu.eg, bttp://orcid.org/0000-0001-5486-5497
}

ABSTRACT. This paper investigates numerically the behavior of Reinforced Concrete (RC) beams, strengthened using Carbon Fiber Reinforced Polymers (CFRP) sheets, subjected to impact loading. Three-dimensional finite element analysis was performed and its results were verified against experimental ones available in the literature showing good agreement. Then, a comprehensive parametric study was performed to investigate the effect of studied parameters on the strengthened RC beams. The main studied parameters were the type and size of reinforcing bars, geometric characteristics of externally bonded CFRP sheets (width, length, and thickness), impact velocity, and the position of the impactor with respect to the beam. Results showed that the use of externally bonded CFRP sheets enhanced the beam capacity and failure mode, and reduced the mid-span deflection. On the other hand, increasing the impact velocity increased the mid-span displacement, however, the use of CFRP bars as internal reinforcement could reduce the increase in the deflection. Moreover, changing the position of the impact load application showed a significant effect on the mid-span displacement as well as the failure mode of tested beams.

KEYwORDS. Concrete; RC Beams; Finite Element; Carbon Fiber Reinforced Polymers; Impact.

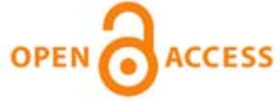

Citation: Emara, M., Elkomy, N., Hassan, H., Numerical Assessment of Reinforced Concrete Beams Strengthened with CFRP Sheets Under Impact Loading, Frattura ed Integrità Strutturale, 58 (2021) 48-64.

Received: 16.04.2021

Accepted: 11.07.2021 Published: 01.10 .2021

Copyright: (C) 2021 This is an open access article under the terms of the CC-BY 4.0, which permits unrestricted use, distribution, and reproduction in any medium, provided the original author and source are credited.

\section{INTRODUCTION}

$\mathrm{I}$ mpact loading research has significant civil engineering applications, such as crash barrier design, structural impact resistance design toward military and terrorist attack, rock fall, vehicle collision, inadvertently dropping heavy objects on buildings, marine buildings impact resistance design, and blonde fence design. Nowadays, Fiber Reinforced Polymers (FRP) materials are being widely used in strengthening and retrofitting Reinforced Concrete (RC) structures due 
to several advantages they provide over the traditional steel plates, such as high tensile strength, high corrosion resistance, ease of use and low cost [1-3]. The utility of using FRP for strength beams subjected to static loads has been extensively studied, although minimal studies have been identified to strengthen Carbon FRP (CFRP) for beams subjected to impact loads [4-6]. Many studies had investigated experimentally and analytically the dynamic response of RC beams under impact load. The dynamic response to the impact load of RC beams was tested experimentally and analytically by Fujikake et al. [7]. Twelve RC beams had been tested under the drop weight induced impact load. The influence of the weight drop height and the amount of longitudinal reinforcing steel in the beam on the dynamic response of RC beams were the main parameters of the study. The results showed that the local failure was minimized by raising the longitudinal steel reinforcement. Moreover, the amount of bottom longitudinal steel reinforcement influenced the local damage close to the impact point. For RC beams failing in flexure, a strong agreement between experimental and analytical results was observed. The impact behavior of FRP-strengthened RC beams without stirrups was studied by Pham and Hao [8]. The author performed dropweight testing on thirteen beams that had been wrapped in different ways to strengthen them in shear. Experimental results showed the possibility of estimating the FRP contribution to shear strength with fair precision by the method recommended by ACI 440.2R-08 [9]. However, under impact loads, the FRP debonding strain is significantly lower than that under quasistatic loads. Therefore, to achieve better estimations, actual debonding strains of FRP were recommended for impact loads. Kantar et al. [10] performed an experimental and theoretical analysis investigating the influence of concrete compressive strength on the impact behavior of RC beams. Testing of two sets of five beams manufactured with normal and high concrete compressive strength was part of the experimental program. Under impact loading, all beams were tested, using a drop hammer from five various heights. The results indicated that the compressive strength of concrete influenced the mode of failure of RC beams. A greater number of drops were also expected for beams with high compressive strength than those with normal compressive strength. More energy was also consumed by normal compressive strength concrete beams compared to high-strength beams. Numerical analysis was performed to simulate the tested beams under impact loading. The verification contrasted the results of the finite element model with those of experimental tests. The observations indicated a good agreement between both the finite elements and the experimental results. In order to improve the flexural capacity of RC beams, Erki and Meier [11] conducted experimental tests on four externally reinforced RC beams under impact loading. Two beams were strengthened using CFRP laminates, while the other two beams were strengthened using steel plates. The impact load was created by lifting and dropping a weight on simply supported beams from the height provided. Results have shown that the energy absorption of CFRP laminate beams is lower than that of external steel plate reinforced beams. Tang and Saadatmanesh[12] conducted an experimental study to investigate the impact behavior of RC beams externally reinforced using FRP sheets. The results indicated that the bending strength and stiffness of retrofitted RC beams can be greatly improved by the composite sheets. Esfahani et al. [13] studied the flexural strength of RC beams strengthened with CFRP sheets. Steel reinforcement ratio, length, width and number of CFRP layers were the experimental variables. Twelve RC beams and three different steel reinforcement ratios were used. Three beams were regarded as control beams, while nine RC beams were externally strengthened using CFRP laminates. The results showed an improvement in flexural strength of RC beams strengthened with CFRP laminates over that of control beams. Compared with the maximum longitudinal reinforcement steel ratio, the improvement in flexural strength is overestimated when using small steel reinforcement ratios. The proportion of the increase in flexural strength of the strengthened beams was influenced by the steel bar size. Increasing the bar size decreased the carrying capacity of the load, which increased even as the number of CFRP layers increased due to the debonding of CFRP laminate in strengthened beams. In beams with large steel bars, the CFRP debonding occurs faster than in beams with small steel bar sizes. High bending load resisted the wide bar size steel bars beams and this caused high tensile stresses in the steel bars. The behavior of RC beams under quasi-static and impact loading conditions has been investigated by Banthia and Mindess [14]. Twelve specimens of reinforced concrete beams had been tested, two of them under quasi-static loading and the others under impact loading. One RC beam was strengthened with GFRP sheets for quasi-static and impact loading. The results indicated that the capacity of the beam under quasi-static load is greater than that of beams under dynamic loading. Watstein [15] carried out dynamic experiments on RC beams, the results showed that under dynamic loads the compressive strength of concrete increased 85 to 100 percent compared to that of static conditions. Experimental research on concrete beams strengthened with GFRP bars under static and impact loading was conducted by GoldSton et al.[16]. They conducted experimental experiments on twelve RC beams with the aim of investigating the effect of GFRP reinforcement on the strength of the concrete beam subjected to static and dynamic loading. They showed that under static loading conditions, the higher GFRP reinforcement ratio resulted in a higher cracking rate and less ductility. On the other hand, the strength of the beams was $15-20 \%$ percent higher than the strength obtained by the static loading conditions under dynamic loads. The bond between FRP and concrete under quasi-static and impact loadings was studied by Khalighi[17]. They carried out experimental studies on FRP reinforced concrete beams and showed an improvement in the beams' bearing capacity. A new heavy-drop weight impact test machine was designed and produced 
by Al-Farttoosi, Mahdi [18] to perform the experimental work to study the impact behavior of the CFRP strengthened concrete beams. To strengthen the RC beams, externally bonded reinforcement (EBR) was used. The width and height of the beams measured were $150 \mathrm{~mm}$ and $200 \mathrm{~mm}$ respectively and $3150 \mathrm{~mm}$ long with a clear span of $3000 \mathrm{~mm}$. The results indicated that the force of impact encountered by the strengthened beams was lower than that of the control beam. CFRP increased the beam stiffness in strengthened beams, decreased the width of the cracks and their propagation, and decreased both the deformation of the beam and the number of cracks. Under impact loading, the CFRP significantly reduced the residual deflection and maximum deflection of the reinforced beams. The use of CFRP to strengthen the beams diminished the beams' ductility and increased the risk of their sudden failure. Pham and Hao [19] investigated the behavior of reinforced concrete beams strengthened with fiber-reinforced polymers under impact loads. The experimental program included a control beam (RB) and strengthened one (NL1B) tested under impact loads. Longitudinal fiber-reinforced polymer strips were used to strengthen the beam. The experimental results showed that the strengthened beam with CFRP layer is better than the control beam against impact loads. From the analysis of the available literature, it can be concluded that the Finite Element Analysis (FEA) can be considered as a reliable alternative to the expensive and time-consuming experimental approach. Moreover, more research still required to investigate the behavior of RC beams strengthened with FRP materials. For this, this paper investigates numerically the flexural response of RC beams strengthened using CFRP sheets under impact loading. A three-dimensional Finite Element Model (FEM) was developed, and the obtained results were validated against experimental results available in the literature. Then a parametric study was performed considering the flexural reinforcement type, the diameter of reinforcing steel rebars, CFRP sheet width, and the bonded length of the CFRP.

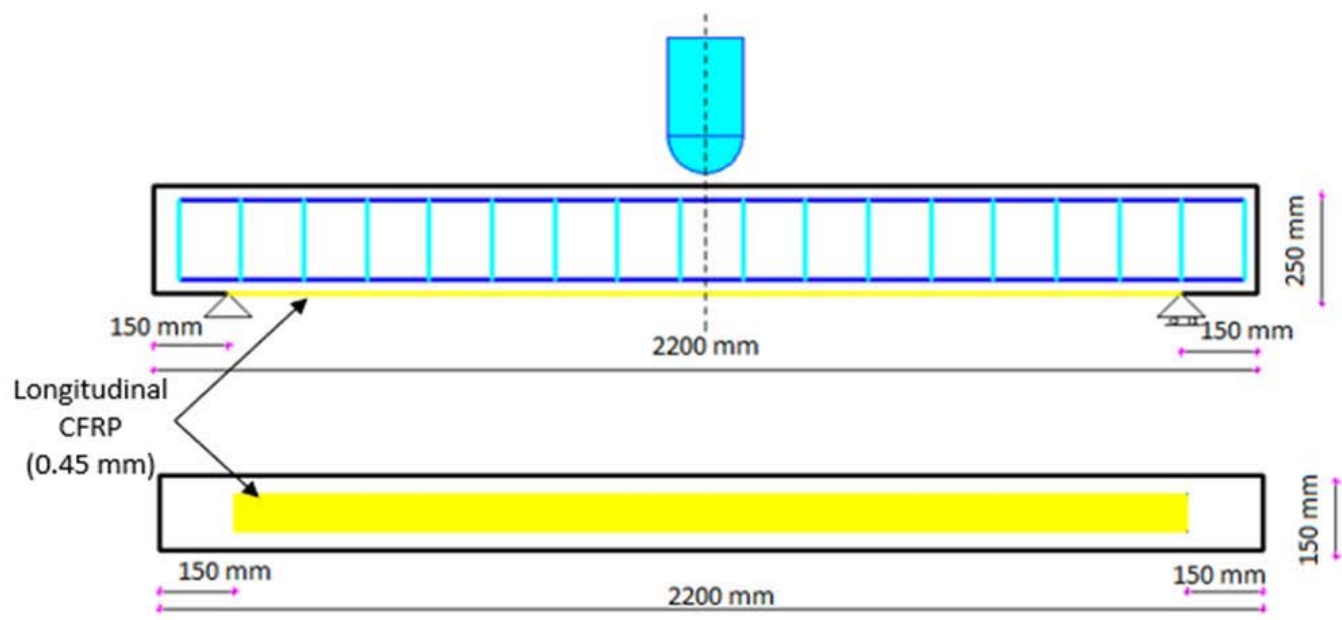

(a)
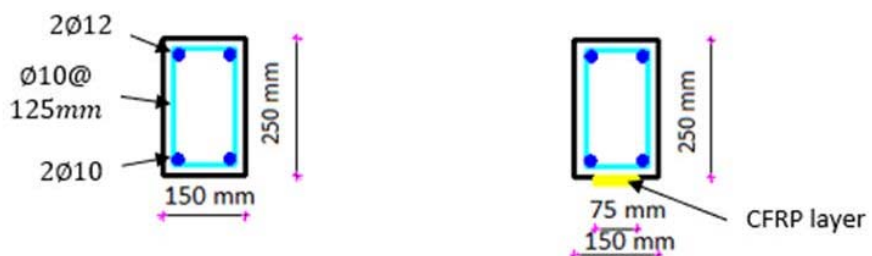

(b)

Figure 1: Details of CFRP strengthened RC beam specimens [19]: (a) Longitudinal section, and (b) Cross-sections.

\section{EXPERIMENTAL WORK}

A n experimental study available in the literature [19] was used to verify and validate the numerical model. In this study, a series of CFRP strengthened RC beams were tested under impact load. The rectangular beam had dimensions of $150 \mathrm{~mm}, 250 \mathrm{~mm}$ and $2200 \mathrm{~mm}$ for the width, height and total length, respectively, with a clear span of $1900 \mathrm{~mm}$ between supports as shown in Fig. 1 . At 28 days of age, the concrete compressive strength was $46 \mathrm{MPa}$. Two steel bars with a diameter of $12 \mathrm{~mm}$ were used at the top of the beam, while two steel bars with a diameter of $10 \mathrm{~mm}$ were used to reinforce the bottom of the beam. For shear reinforcement, $10 \mathrm{~mm}$ steel bars were used. For the total beam length, 
the distance between the stirrups was $125 \mathrm{~mm}$. Steel reinforcement yield strengths (D12, D10) were 500 and $250 \mathrm{MPa}$, respectively. The beam was strengthened in flexure by an externally bonded CFRP sheet, with a nominal thickness of 0.45 $\mathrm{mm}$, the width of the CFRP layer used in the experiments was $75 \mathrm{~mm}$. The tensile strength and elastic modulus of the CFRP sheets were $1548 \mathrm{MPa}$ and $89 \mathrm{GPa}$, respectively. In this analysis, two samples were selected to be simulated and verified. The two samples were an un-strengthened sample (control beam (RB)), and a strengthened sample (NL1B) with CFRP sheet in the longitudinal direction. The impact experiments were conducted out by dropping a mass from a particular height onto the mid-span of the beams. A solid cylinder, of $203.5 \mathrm{~kg}$ weight, was lowered from a vertical height of $2 \mathrm{~m}$ at mid-span to achieve a velocity of $6.3 \mathrm{~m} / \mathrm{sec}$.

\section{NUMERICAL MODELING}

\section{Materials constitutive models}

K nown geometry and mechanical properties of materials are needed for ABAQUS inputs, particularly for concrete materials. Typically, concrete parameters are based on empirical equations linking stress to their corresponding strains. In this research, the principles of the Concrete Damage Plasticity model (CDP) [20-23] were used to link stresses to strains. Due to their versatile utility, the CDP model has been used in various types of loading conditions for instance: static, dynamic or monotonic and cyclic loadings. Compressive and tensile stress-strain under its damage states is considered by the model. For the CDP model available in ABAQUS, Fig. 2 is used to identify the post-failure stress-strain interaction of concrete. Young's modulus $\left(E_{o}\right)$, stress $\left(\sigma_{t}\right)$, cracking strain $\left(\varepsilon_{c k}\right)$ and the damage parameter values $\left(d_{t}\right.$ and $\left.d_{c}\right)$ for the specific concrete grade were the input parameters. The cracking strain $\left(\varepsilon_{c k}\right)$ can be determined by Eqn. (1).

$$
\varepsilon_{c k}=\varepsilon_{t}-\varepsilon_{e l}
$$

where the elastic-strain referring to the undamaged material is $\varepsilon_{e} l=\sigma_{t} / E_{o}$, and $\mathcal{E}_{t}$ is the total tensile strain. Furthermore, the plastic strain $\left(\varepsilon_{p l}\right)$ for concrete tensile behavior can be defined as shown in Eqn. (2):

$$
\varepsilon_{p l}=\varepsilon_{c k}-\frac{d_{t}}{1-d_{t}} \frac{\sigma_{t}}{E_{0}}
$$

A generic diagram of the relationship between compressive stress-strain with damage properties is shown in Fig. 2 (a). The inputs are stresses $\left(\sigma_{c}\right)$ that lead to stress values and damage properties $\left(d_{c}\right)$ with inelastic in tabular format, inelastic strains $\left(\varepsilon_{i n}\right)$. It should be noted that using Eqn. (3), the total strain values should be translated into inelastic strains.

$$
\varepsilon_{i n}=\varepsilon_{c}-\varepsilon_{e l}
$$

where $\varepsilon_{\ell l}$ refers to the strain of undamaged material, and $\boldsymbol{\varepsilon}_{c}$ is the total compressive strain. Moreover, using Eqn. (4), the plastic strain values in compression $\left(\varepsilon_{p}\right)$ can be calculated as follows:

$$
\boldsymbol{\varepsilon}_{p l}=\boldsymbol{\varepsilon}_{c}-\frac{d_{c}}{1-d_{c}} \frac{\sigma_{c}}{E_{0}}
$$

Tab. 1 presents the parameters used to define the CDP model. Steel was modeled as elastic-perfectly plastic material with similar behaviors in tension and compression as shown in Fig. 3. The material properties for the steel reinforcement are as follows: Elastic modulus (Es=200,000) MPa, Poisson's ratio (0.3).

CFRP material was defined using a lamina model in which the elastic moduli, shear moduli in two directions and Poisson's ratio, and CFRP's linear elastic response were defined. ABAQUS/Explicit offers Hashin 's failure criteria[24], widely used to describe the damage in composite materials, in order to implement the damage in the CFRP in this model. In addition to longitudinal and transverse shear strengths, this damage model is identified by supplying CFRP's longitudinal and transverse tensile and compression strengths as presented in Tab. 2. 


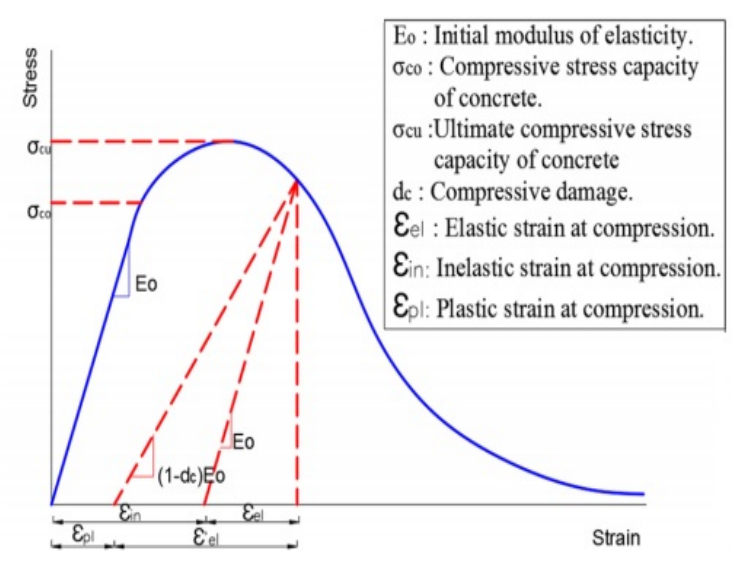

(a)

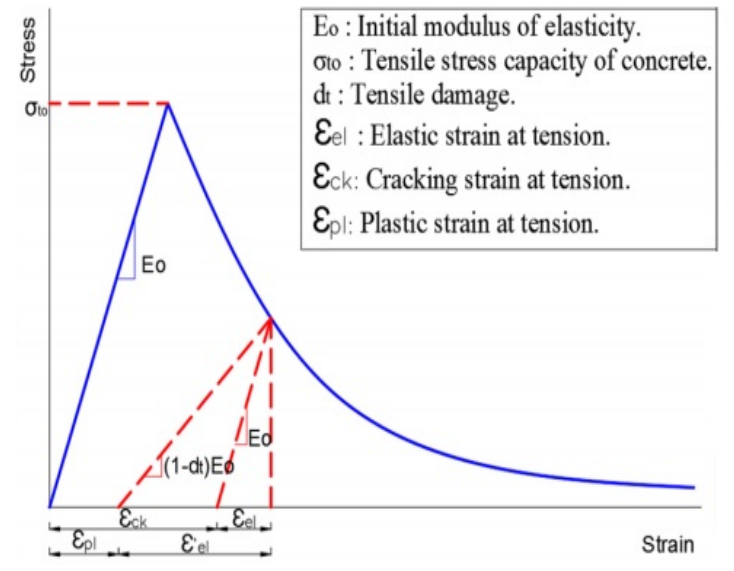

(b)

Figure 2: Concrete damage plasticity model: (a) Compression, and (b) Tension

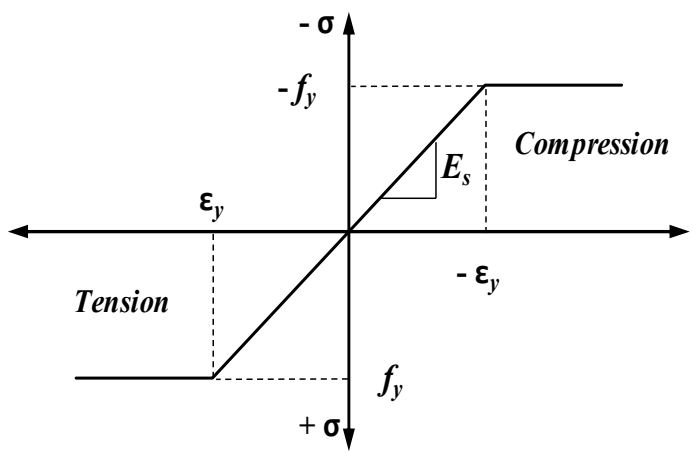

Figure 3: Stress-strain relationship for steel reinforcement

\begin{tabular}{|c|c|c|}
\hline Parameter & Value & Description \\
\hline$\Psi$ & 30 & Dilation angle \\
\hline$\epsilon$ & 0.1 & Eccentricity \\
\hline $\boldsymbol{f} \boldsymbol{b}_{0} / \boldsymbol{f} \boldsymbol{c}_{0}$ & 1.16 & $\begin{array}{l}\text { The ratio of initial equibiaxial compressive yield stress to initial uniaxial } \\
\text { compressive yield stress. }\end{array}$ \\
\hline $\boldsymbol{\mu}$ & 0.0001 & Viscosity Parameter \\
\hline $\boldsymbol{k}$ & 0.667 & $\mathrm{Kc}$, the ratio of the second stress invariant on the tensile meridian \\
\hline
\end{tabular}

Table 1: Material parameters of concrete, based on ABAQUS recommendations.

\begin{tabular}{clcc}
\hline Property & Description & Unit & Value \\
$\boldsymbol{\varrho}$ & Density & $\mathrm{kg} / \mathrm{m}^{3}$ & 1600 \\
$\mathbf{E}_{1}$ & Elastic modulus in longitudinal (fiber) direction & $\mathrm{GPa}$ & 89 \\
$\mathbf{E}_{2}$ & Elastic modulus in transverse (matrix) direction & $\mathrm{GPa}$ & 17 \\
$\mathbf{G}_{12}$ & In-plane shear modulus & $\mathrm{GPa}$ & 6 \\
$\boldsymbol{\sigma}_{1 \mathrm{t}}$ & Longitudinal tensile strength & $\mathrm{MPa}$ & 1548 \\
$\boldsymbol{\sigma}_{1 \mathrm{c}}$ & Longitudinal compressive strength & $\mathrm{MPa}$ & 1200 \\
$\boldsymbol{\sigma}_{2 \mathrm{t}}$ & Transverse tensile strength & $\mathrm{MPa}$ & 50 \\
$\boldsymbol{\sigma}_{2 \mathrm{c}}$ & Transverse compressive strength & $\mathrm{MPa}$ & 250 \\
$\boldsymbol{\tau}_{12}$ & In-plane shear strength & $\mathrm{MPa}$ & 70 \\
\hline
\end{tabular}

Table 2: CFRP material properties. 
Model built-up, boundary conditions, and interaction properties.

Solid elements (C3D8R) Available in the ABAQUS / Explicit element library with three degrees of freedom (8-nodes) were used to model the reinforced concrete beams studied in this paper. The concrete parameters in Tab. 1 are needed to completely describe the CDP model, and their numerical parameters were chosen based on SIMULIA [25] recommendations. A two-node linear displacement beam element (B31) was chosen to reflect the internal reinforcement (main reinforcement and stirrups). Using a discrete rigid body as a reference point, the impactor was modelled to provide the hammer's mass. The discrete rigid body was selected as no deformation occurred in the experimental investigation [18]. In order to simulate the CFRP, Shell elements (S4R) were employed. CFRP mechanical properties used in the current study are shown in Tab. $2[19,26]$. To represent the bond between longitudinal and transverse reinforcements with concrete, embedded region coupling was used. This coupling allows one region to be identified by the user as the host and another as embedded. Reinforcements reflected the embedded region in this model, and the host region was the concrete beam [27]. Cohesive elements, six degrees of freedom per node (COH3D8), have been used to model the contact region between CFRP and the concrete beam. This type of element has been commonly used to identify this type of contact zone [28]. By using the contact pair possible choice in ABAQUS/Explicit, the interaction between the impactor and the tested beams was established. To implement the ABAQUS/Explicit contact pair algorithm, it is important to define the master and slave surfaces. In order to describe these surfaces, a few rules should be followed. Among these guidelines, the softer underlying material should be the slave surface. The impactor was therefore viewed as a master surface, while the impacted member (RC beam) was selected to be a slave surface [28, 29]. Coupling restriction was made to prevent the scattering of results. A reference point (RP) placed at the center of the support on the bottom of the projectile creates this coupling restriction. The loading is exercised at the mid-span of the beam via a hammer for impact, and a surface-to-surface constraint was used. Consequently, at one point, one might obtain force-displacement results with minimal errors. As the beams were simply supported, the degrees of freedom of U1, U2, and U3 were set to zero. Several mesh sizes were used to calibrate the FE model, and finally, a mesh size equal to $20 \mathrm{~mm}$ was selected for providing acceptable results while keeping lower computational time. Fig. 4 demonstrates the arrangement of reinforcing bars, RC beams, supports, and hammer in the ABAQUS program [27].
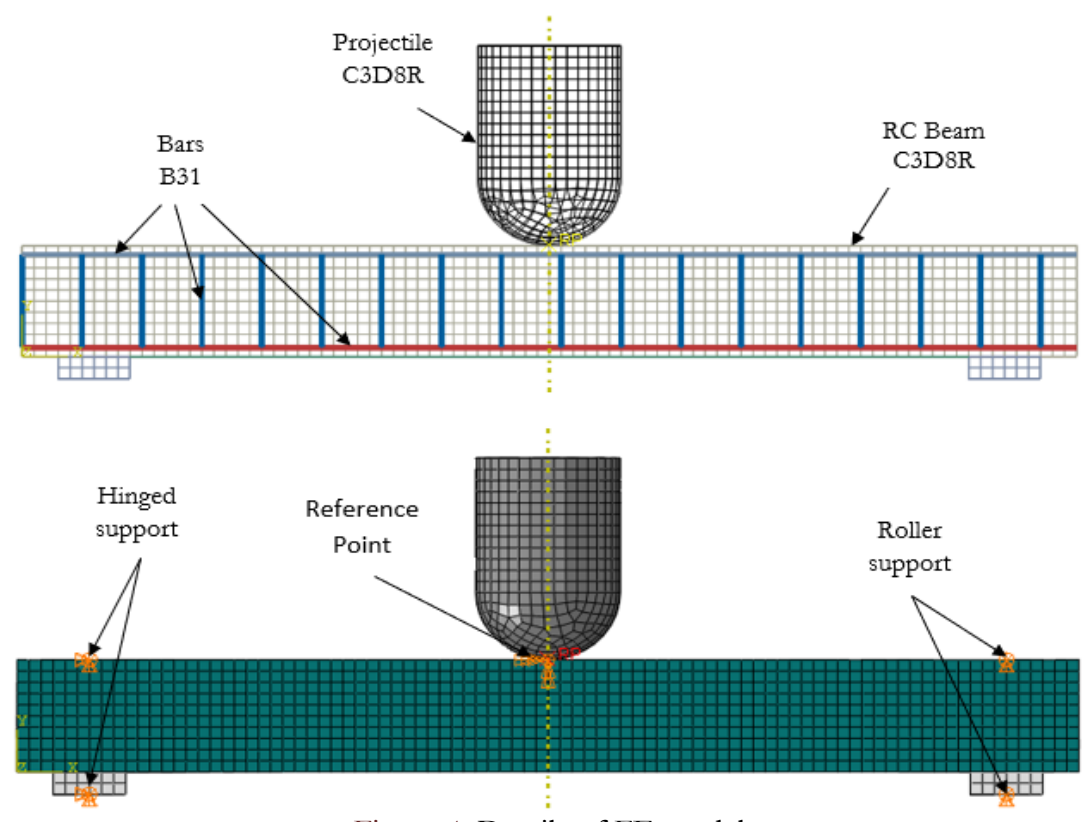

Figure 4: Details of FE model.

\section{RESULTS AND VERIFICATIONS}

$\mathrm{F}$ igs. 5-7 and Tabs. 3 and 4 verify the comparison between ABAQUS modeling and the experimental tests of Pham and Hao [19]. Fig. 5 shows the impact force-time history $(F-t)$ curves for the two specimens chosen from Pham and Hao [19], comparing FE predictions and experimental data. The comparison demonstrates the capability of the developed FE model to predict the (F-t) curves of RC beams strengthened in flexure under impact load, with reasonable 
accuracy. In addition to the general response, the model must be able to accurately predict the key points within the curve, which are: (1) the maximum impact force $\left(F_{\max }\right),(2)$ maximum displacement $\left(\Delta_{\max }\right)$; (3) residual displacement $\left(\Delta_{\mathrm{R}}\right)$; (4) and impact duration $(D)[30]$. The FE predictions for $F_{\max }, \Delta_{\max }$, and $\Delta_{\mathrm{R}}$ agreed very well with the experimental data, with a percentage difference of $2.35-7.99 \%$ for $F_{\max }, 1.74-7.62 \%$ for $\Delta_{\max }$, and $6.6-16 \%$ for $\Delta_{\mathrm{R}}$. Tab. 3 shows that the percentage of difference between FE and test for impact period predictions $(D)$ varied between 16 to $18 \%$. This may be due to a variety of fixity conditions in the actual test that can't be numerically captured, the damping force generated by the testing rig, model limitations in terms of material idealization and mesh, or a combination of these factors. However, the observed difference in $D$ is within the acceptable maximum range found in the literature [31] and doesn't affect the overall accuracy of the model's results. Fig. 6 shows the displacement-time histories $(D-t)$ for the modelled beams. It can be shown in this figure that the overall displacement of strengthened beams is usually less than that of un-strengthened beams, with different values depending on the CFRP configuration. In addition, the comparison between the experimental and FE $(\Delta-\mathrm{t})$ history confirmed the capability of developed models in capturing these curves very well, for both, the un-strengthened samples, and this strengthened by longitudinal CFRP sheet. Furthermore, CFRP strengthening can be considered an effective method to reduce impact and blast loads. Fig. 7 shows that the reaction forces began as negatives due to the Rayleigh wave as described above, then increased to maximum values in the positive region due to the global equilibrium of the beam against impact loadings, before returning to negatives due to free vibrations of the beam. The first maximum negative reaction forces associated with beam-free vibrations were greater than their second counterparts. Another way to validate the accuracy of a developed model is the concrete crack pattern. In most cases, the cracking patterns in ABAQUS are visualized by plotting the concrete principal strains[32]; but in this analysis, a more precise methodology is used by enabling and plotting the tensile damage parameter $\left(d_{t}\right)$ in the CDP model. Tab. 4 shows the experimental and FE predicted cracks patterns for two beams from the experiment set [19]. The crack patterns from the model were almost identical to those occurring in the experimental tests.

\begin{tabular}{|c|c|c|c|c|c|c|c|c|c|c|c|c|}
\hline \multirow[t]{2}{*}{ Sample } & \multicolumn{3}{|c|}{$\begin{array}{l}\text { Peak Impact force } \\
\qquad \begin{array}{c}\left(F_{\max }\right) \\
(\mathrm{KN})\end{array}\end{array}$} & \multicolumn{3}{|c|}{$\begin{array}{c}\text { Maximum } \\
\text { Displacement }\left(\Delta_{\max }\right) \\
(\mathrm{mm})\end{array}$} & \multicolumn{3}{|c|}{$\begin{array}{l}\text { Residual Displacement } \\
\qquad \begin{array}{c}\left(\Delta_{R}\right) \\
(\mathrm{mm})\end{array}\end{array}$} & \multicolumn{3}{|c|}{$\begin{array}{l}\text { Duration (D) } \\
\quad(\mathrm{ms})\end{array}$} \\
\hline & EXP & FEM & Diff\% $\%$ & EXP & FEM & Diff\% $\%$ & EXP & FEM & Diff $\%$ & EXP & FEM & $\begin{array}{c}\text { Diff } \\
\%\end{array}$ \\
\hline $\mathrm{RB}$ & 453 & 442.4 & $2.4 \%$ & 52.3 & 51.4 & $1.7 \%$ & 41.6 & 49.5 & $16 \%$ & 39 & 32 & $18 \%$ \\
\hline NL1B & 470 & 510.9 & $8 \%$ & 41.1 & 38 & $7.6 \%$ & 31.2 & 33.4 & $6.6 \%$ & 38 & 32 & $16 \%$ \\
\hline
\end{tabular}

Table 3: Comparison between experimental and FE results.

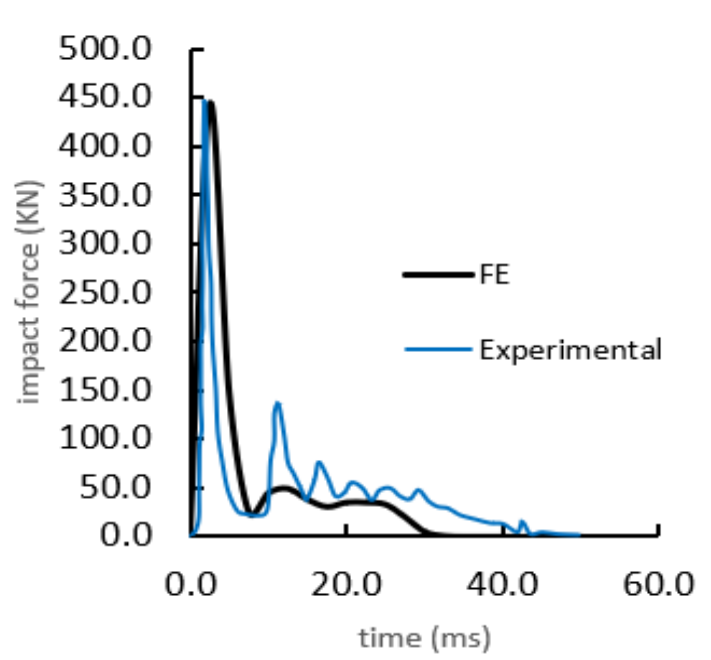

(a)

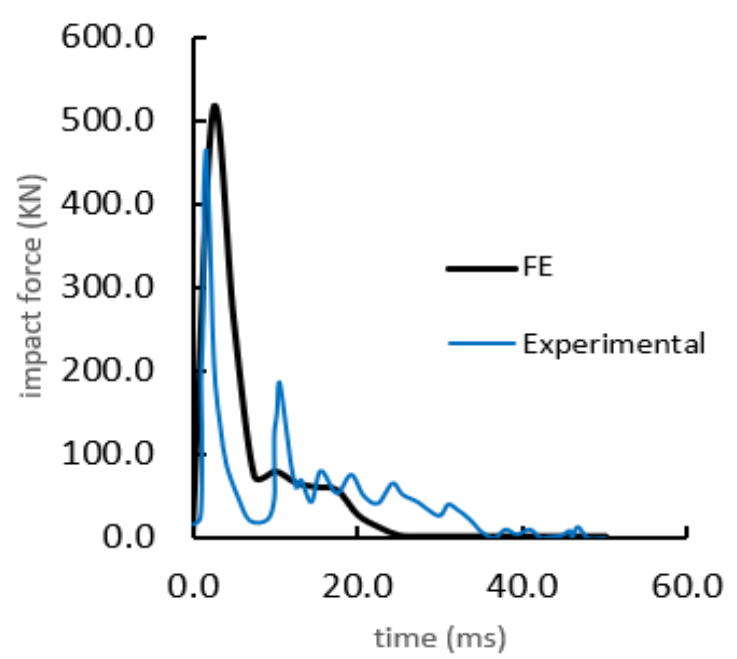

(b)

Figure 5: FE versus experimental impact force-time histories: (a) Beam RB, and (b) Beam NL1B. 


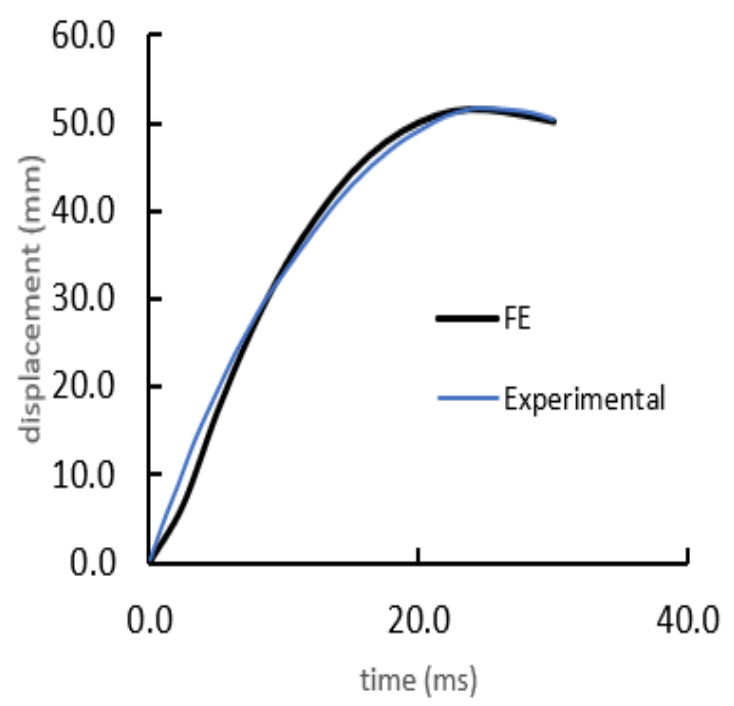

(a)

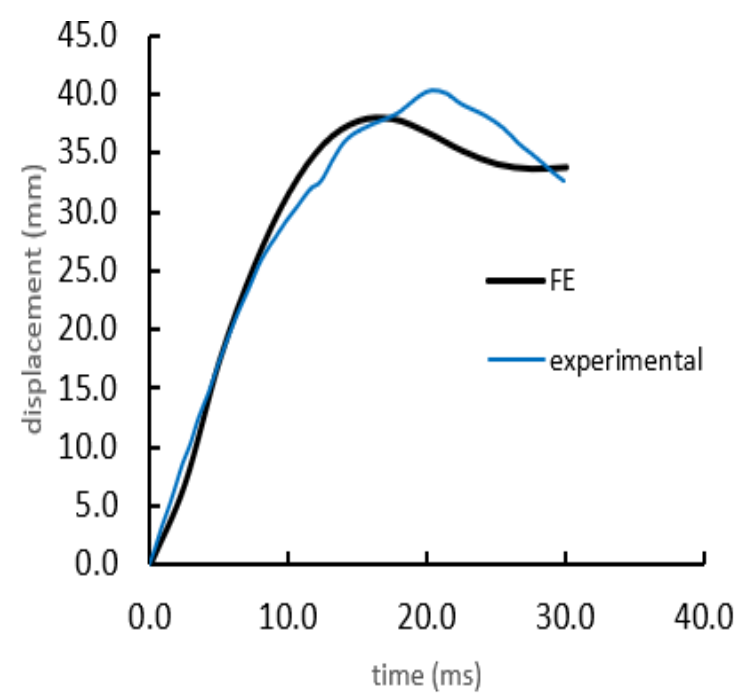

(b)

Figure 6: FE versus experimental displacement-time histories: (a) Beam RB, and (b) Beam NL1B.

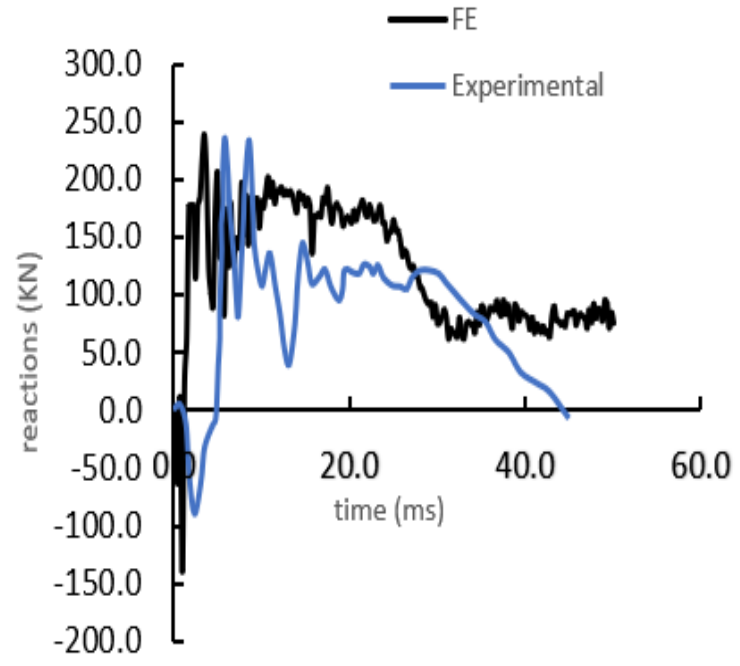

(a)

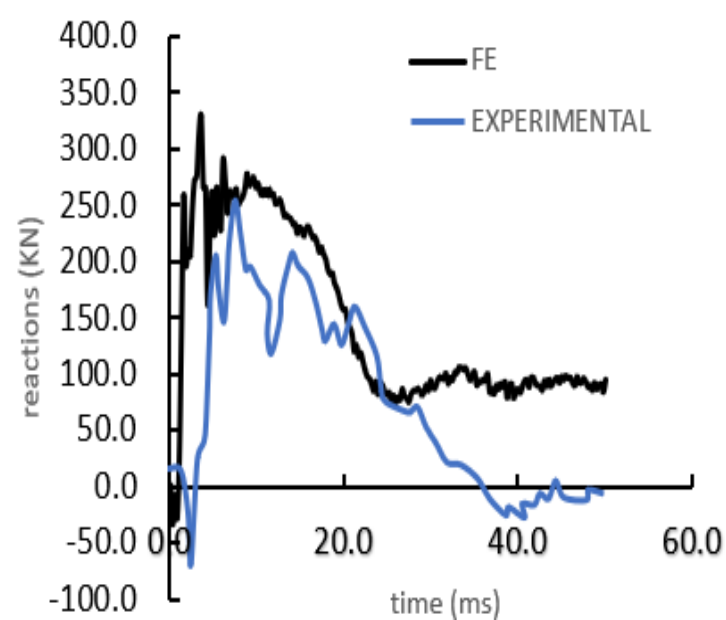

(b)

Figure 7: FE versus experimental reactions-time histories: (a) Beam RB, and (b) Beam NL1B.

\section{PARAMETRIC STUDY}

$\mathrm{D}$ ue to the scarcity of studies on RC beams strengthened in flexure and subjected to impact loading, the optimized FE model presents a great opportunity to investigate the behavior of these members in depth and to perform a detailed parametric study on the effects of several variables that are designed to affect the member's capacity. The following sections discuss the parametric analysis carried out concerning the type and diameter of reinforcement bars, geometric parameters of CFRP layer of externally bond reinforcement EBR (width, length and thickness), impact velocity and position of the impactor in relation to the length of the beam. As shown in Tab. 5, fourteen specimens were strengthened using CFRP sheets. The length and width of CFRP sheet varied in different specimens. Two specimens were kept without change in CFRP length or width, but reinforcement changed only. Specimens are named as follows; Ba-bDcLd. The letters a, b, c, and d refer to beam number, tensile bar diameter, the width of layer and length of CFRP sheet, respectively. 


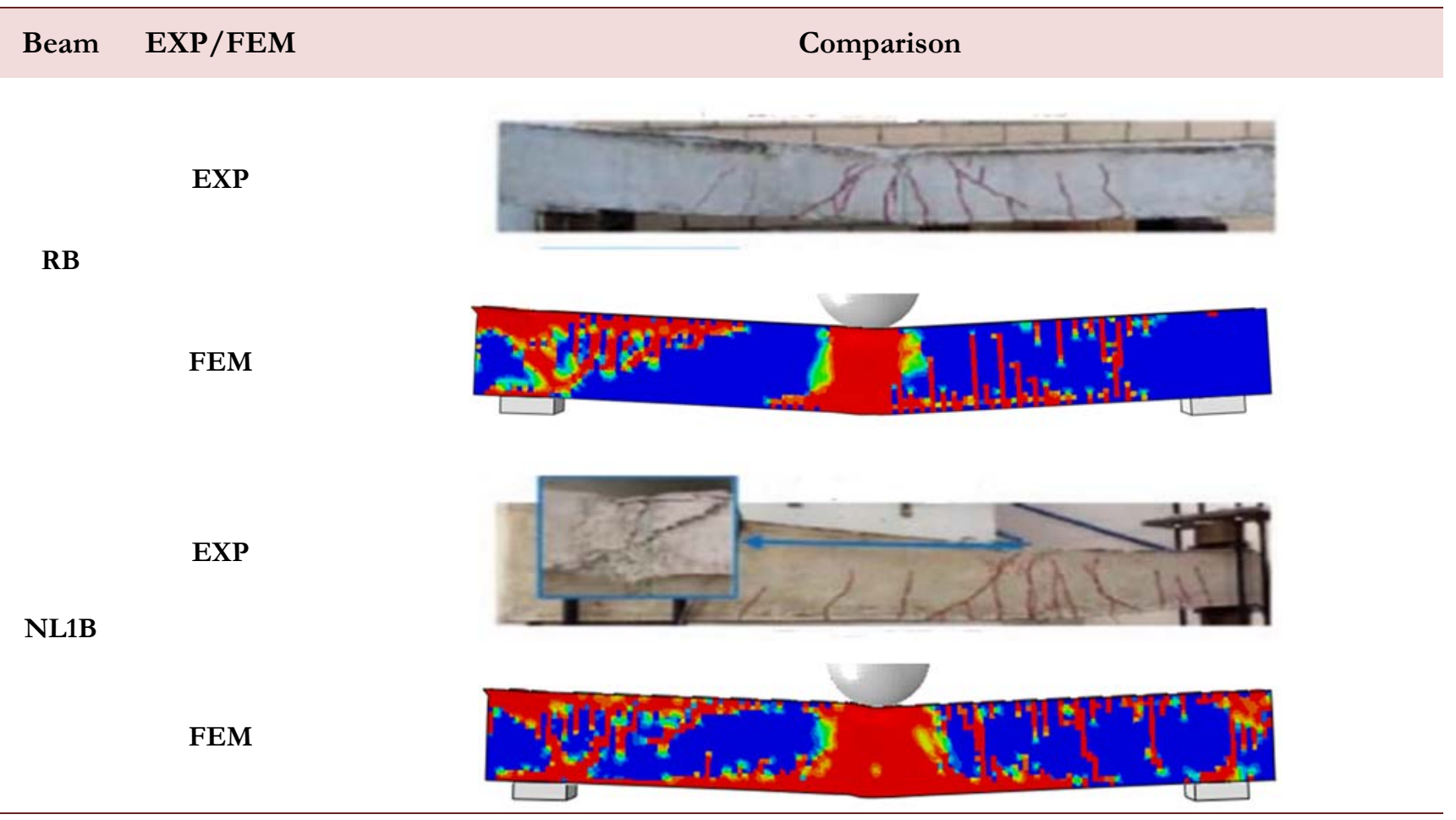

Table 4: FE versus experimental failure modes.

\begin{tabular}{|c|c|c|c|}
\hline Samples & reinforcement & $\begin{array}{c}\text { Parameters } \\
\text { Width of CFRP sheet } \\
(\mathrm{mm})\end{array}$ & $\begin{array}{l}\text { Length of CFRP sheet } \\
\text { (mm) }\end{array}$ \\
\hline B1-8D & $\mathrm{Ph} 8$ & 75 & Full length \\
\hline B2-10D & $\mathrm{Ph} 10$ & 75 & Full length \\
\hline B3-12D-75L600 & & & 600 \\
\hline B4-12D-75L1200 & & 75 & 1200 \\
\hline B5-12D-75L full & $\mathrm{Ph} 12$ & & Full length \\
\hline B6-12D-150L600 & & & 600 \\
\hline B7-12D-150L1200 & & 150 & 1200 \\
\hline B8-12D-150L full & & & Full length \\
\hline B9-cbD-75L600 & & & 600 \\
\hline B10-cbD75L1200 & & 75 & 1200 \\
\hline B11-cbD-75L full & CFRP bars & & Full length \\
\hline B12-cbD-150L600 & & & 600 \\
\hline B13-cbD-150L1200 & & 150 & 1200 \\
\hline B14-cbD-150L full & & & Full length \\
\hline
\end{tabular}

Table 5: Parametric study specimens.

In order to reduce the displacement of beams showed in the experimental study of Pham and Hao and the proposed FE model, some adjustments were made to the model. Figs. 8 and Tab. 6 show the effect of reinforcement changes on displacement-time $(D-t)$, impact force-time $(F-t)$ curves, and failure modes. Three different diameters were used to reinforce RC beams $(8,10$ and $12 \mathrm{~mm})$, moreover reinforcing steel bars were replaced by CFRP bars. These beams are represented as (B1-8D, B2-10D, B5-12D-75L full and B11-cbD-75L full). From these changes, it is noted that the deflection had reduced by $(6.6,14.8,29.1 \%)$ when using gradually change in diameters from D8 to CFRP bars. 


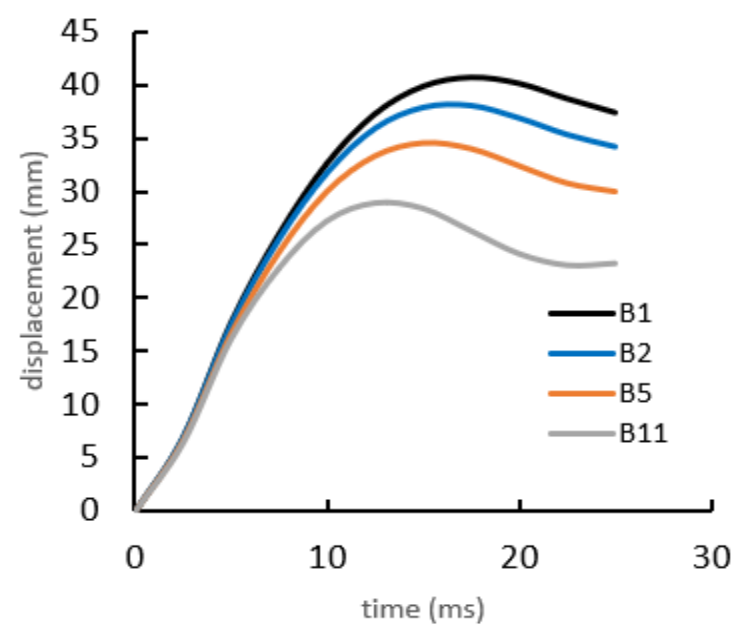

(a)

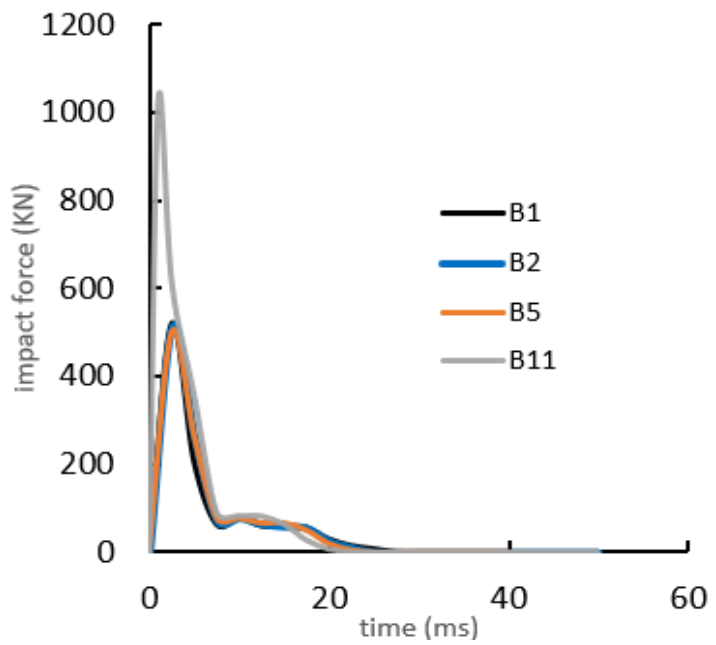

(b)

Figure 8: Effect of reinforcement type and diameter: (a) Displacement-time histories, and (b) Impact force-time histories.

Sample

B1-8D

B2-10D

B5-12D-75L full

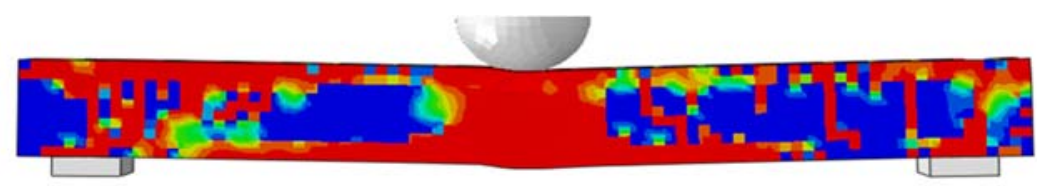

B11-cbD-75L full

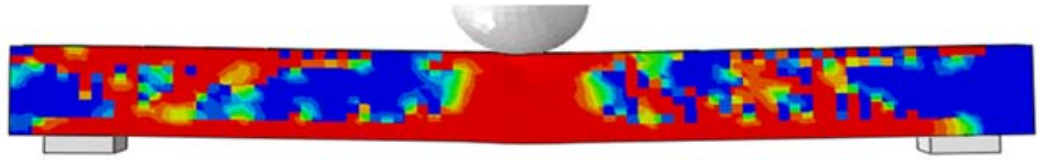

Table 6: various reinforcement types and diameters (failure modes).

To increase the bending resistance of the reinforced concrete beams, it's suggested to strength beams with one layer of CFRP with different lengths $(600 \mathrm{~mm}, 1200 \mathrm{~mm}$ and full beam length) as shown in beams (B3-12D-75L600, B4-12D75L1200, B5-12D-75L full) (B6-12D-150L600, B7-12D-150L1200, B8-12D-150L full) (B9-cbD-75L600, B10-cbD75L1200, B11-cbD-75L full) (B12-cbD-150L600, B13-cbD-150L1200, B14-cbD-150L full). When using steel bars (Ph 12) in reinforcement there was a significant change in displacement results by $(2.1,7.3 \%),(8.4,10.8 \%)$ and impact forces results by $(1.7,4.3 \%),(2.2,4.2 \%)$ as shown in Figs. 9 and 10 (a) for $75 \mathrm{~mm}$ width of CFRP layer and (b) for $150 \mathrm{~mm}$ width of CFRP layer, respectively. Whereas, when using CFRP bars for reinforce beams, there was a slight change in the results when changing the length of the strengthening layer as shown in Figs. 9 and 10 (c) and (d). 


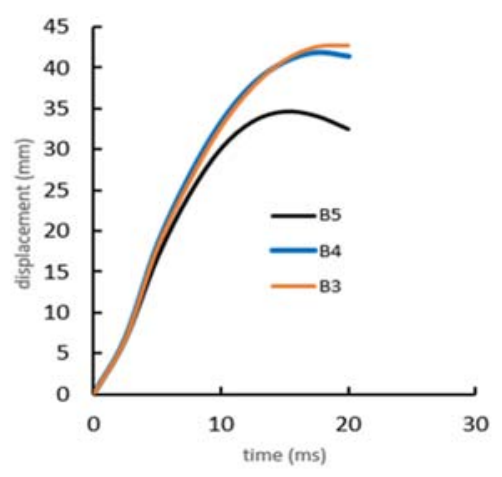

(a)

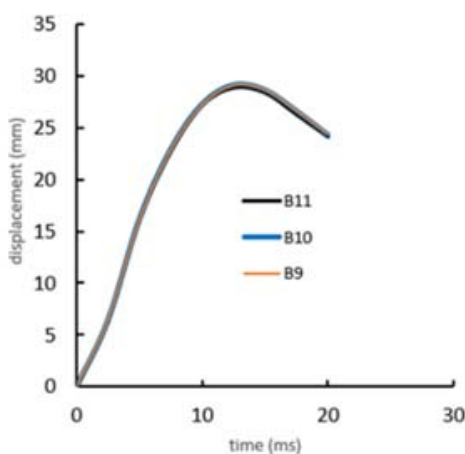

(c)

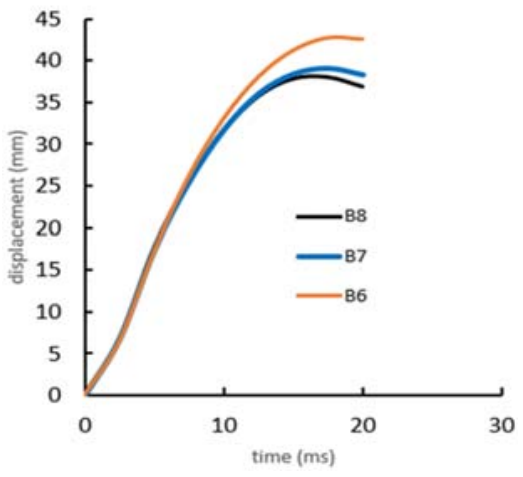

(b)

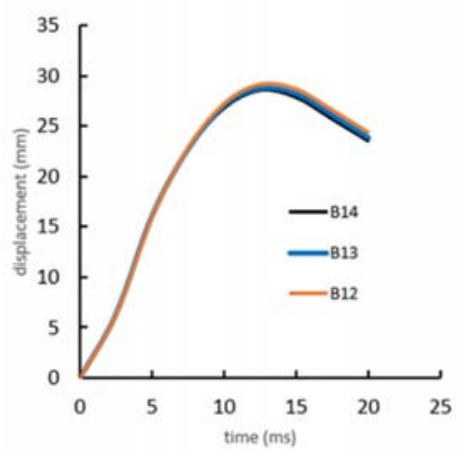

(d)

Figure 9: Effect of the length of CFRP layer for strengthening on the displacement-time histories.

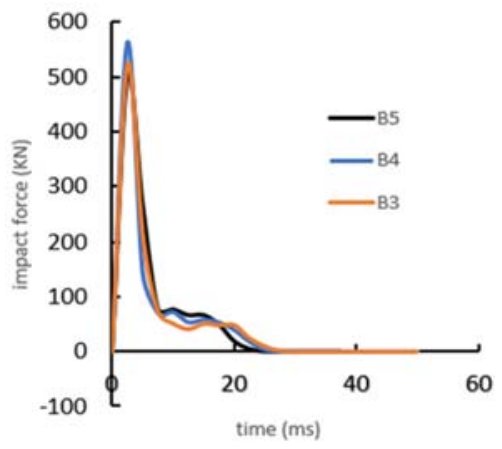

(a)

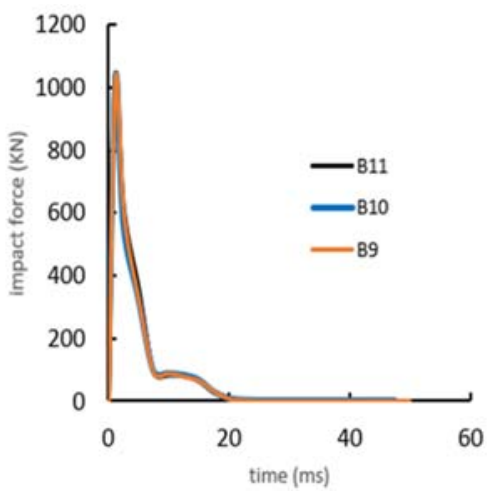

(c)

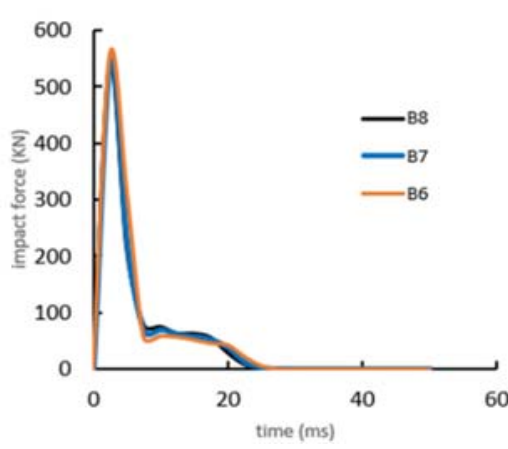

(b)

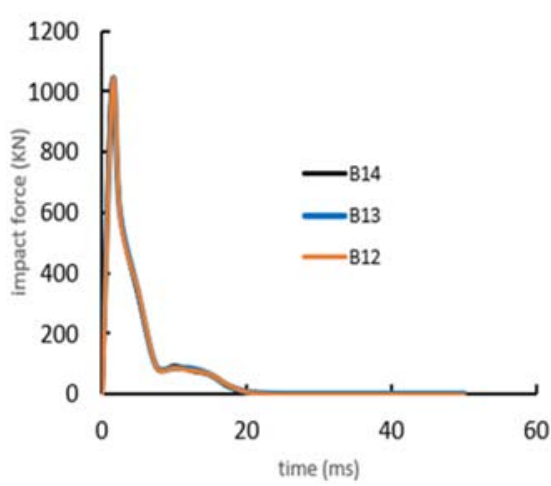

(d)

Figure 10: Effect of the length of CFRP layer for strengthening on impact force-time histories. 
According to Tab. 5 and Fig. 11, for beams (B4-12D-75L1200, B7-12D-150L1200, B10-cbD75L1200, and B13-cbD150L1200), there was a change in the width of the CFRP strengthening layer ( $75 \mathrm{~mm}$ and $150 \mathrm{~mm}$ ) when using $\mathrm{Ph} 12$ and CFRP bars for reinforcement at $1200 \mathrm{~mm}$ length of strengthening layer. These changes leading to reduce deflection by 6.5 and $1.7 \%$ and impact load by 2.7 and $0.3 \%$ for Ph 12 and CFRP bars reinforcement, respectively.

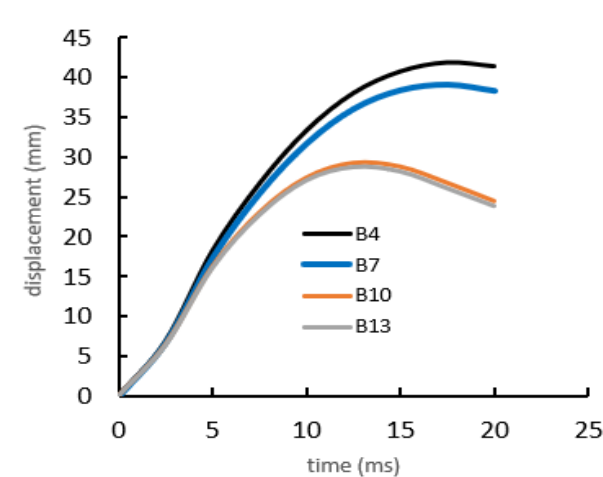

(a)

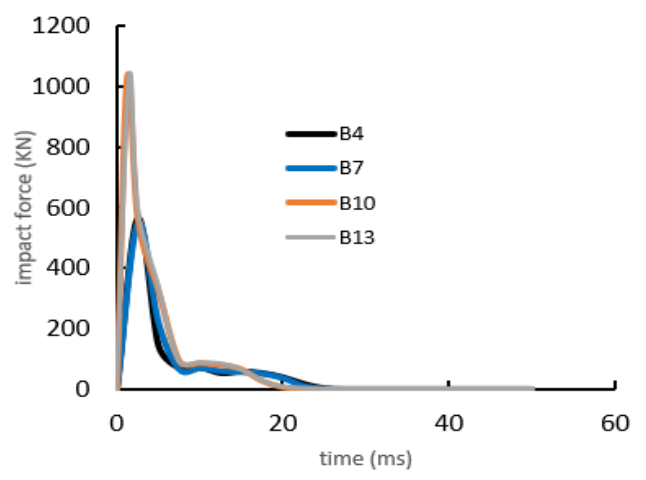

(b)

Figure 11: Time-deflection curve

\begin{tabular}{|c|c|c|c|c|}
\hline \multirow[b]{2}{*}{ Samples } & \multicolumn{4}{|c|}{ Parameters } \\
\hline & Reinforcement & $\begin{array}{l}\text { Impact Velocity } \\
\text { (v) } \mathrm{m} / \mathrm{s}\end{array}$ & $\begin{array}{c}\text { Position of } \\
\text { Impactor (L) } \mathrm{mm}\end{array}$ & $\begin{array}{l}\text { Thickness of CFRP } \\
\text { Layer (th) mm }\end{array}$ \\
\hline C1 & Steel bars & & & 0.45 \\
\hline C2 & & 5.2 & 1100 & 0.9 \\
\hline C3 & & & & 1.8 \\
\hline $\mathrm{C} 4$ & & & & 0.45 \\
\hline C5 & & 6.3 & 1100 & 0.9 \\
\hline C6 & & & & 1.8 \\
\hline C7 & & & & 0.45 \\
\hline $\mathrm{C} 8$ & & 6.3 & 550 & 0.9 \\
\hline C9 & & & & 1.8 \\
\hline C10 & & & & 0.45 \\
\hline C11 & & 8.5 & 1100 & 0.9 \\
\hline $\mathrm{C} 12$ & & & & 1.8 \\
\hline C13 & CFRP bars & & & 0.45 \\
\hline C14 & & 5.2 & 1100 & 0.9 \\
\hline C15 & & & & 1.8 \\
\hline C16 & & & & 0.45 \\
\hline C17 & & 6.3 & 1100 & 0.9 \\
\hline C18 & & & & 1.8 \\
\hline C19 & & & & 0.45 \\
\hline $\mathrm{C} 20$ & & 6.3 & 550 & 0.9 \\
\hline C21 & & & & 1.8 \\
\hline $\mathrm{C} 22$ & & & & 0.45 \\
\hline $\mathrm{C} 23$ & & 8.5 & 1100 & 0.9 \\
\hline $\mathrm{C} 24$ & & & & 1.8 \\
\hline
\end{tabular}

Table 7: Additional parametric study samples. 
Models (B8-12D-150L full and B14-cbD-150L full), which are shown in Tab. 5 and discussed in the previous section, were selected to perform the following parameters: impact velocity $(\mathrm{v}) \mathrm{m} / \mathrm{s}$, the position of impactor from the left support at distance (L) $\mathrm{mm}$ and thickness of CFRP layer (th) $\mathrm{mm}$ as shown in Tab. 7. The effects of impact velocity (v) on the behavior of RC beam strengthened with CFRP against impact loading were investigated by using three values for $\mathrm{v}(5.2,6.3$, and 8.5 $\mathrm{m} / \mathrm{s})$. Fig. 12 plots $(D-t)$ histories for strengthened beams with a $0.45 \mathrm{~mm}$ thickness of CFRP layer for reinforced beams with $\mathrm{Ph} 12 \mathrm{~mm}$ in (a) and CFRP bars in (b), for the three selected velocities; while Fig. 13 shows the relation between $\Delta_{\max }$ and $\mathrm{v}$ for the same samples. Comparing the strengthened beam with $0.45 \mathrm{~mm}$ CFRP layer for Ph 12 and CFRP bars reinforcement, $\Delta_{\max }$ increased for $\mathrm{v}=5.2,6.3$, and $8.5 \mathrm{~m} / \mathrm{s}$, respectively. This shows that CFRP reinforcement can significantly improve the beam's resistance to impact, at various impact energy values.

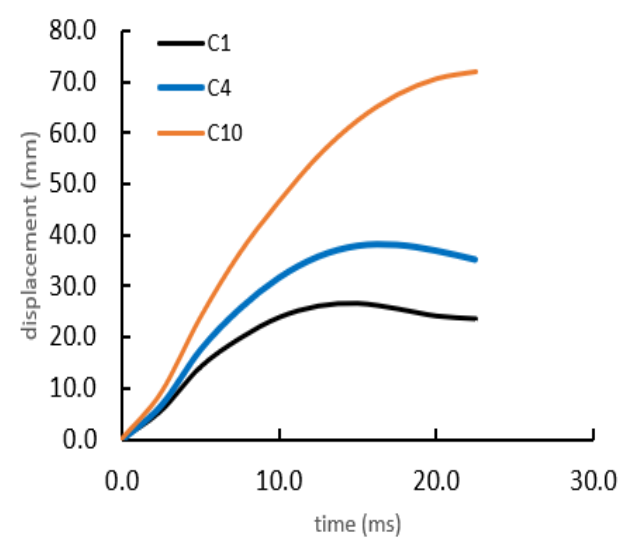

(a)

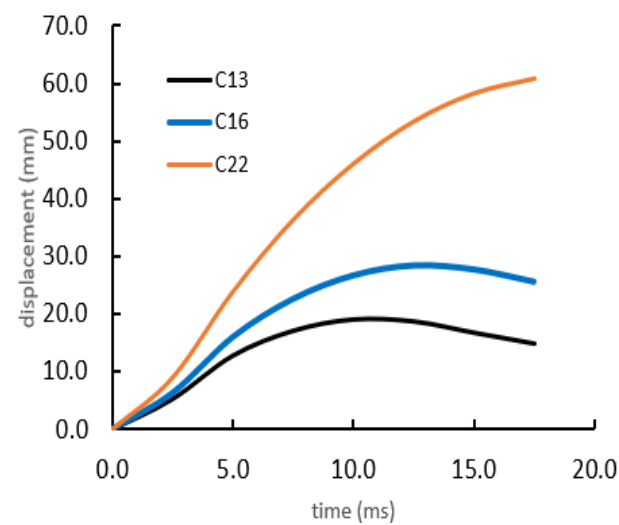

(b)

Figure 12: Strengthened RC beams with various impact velocities (displacement-time histories)

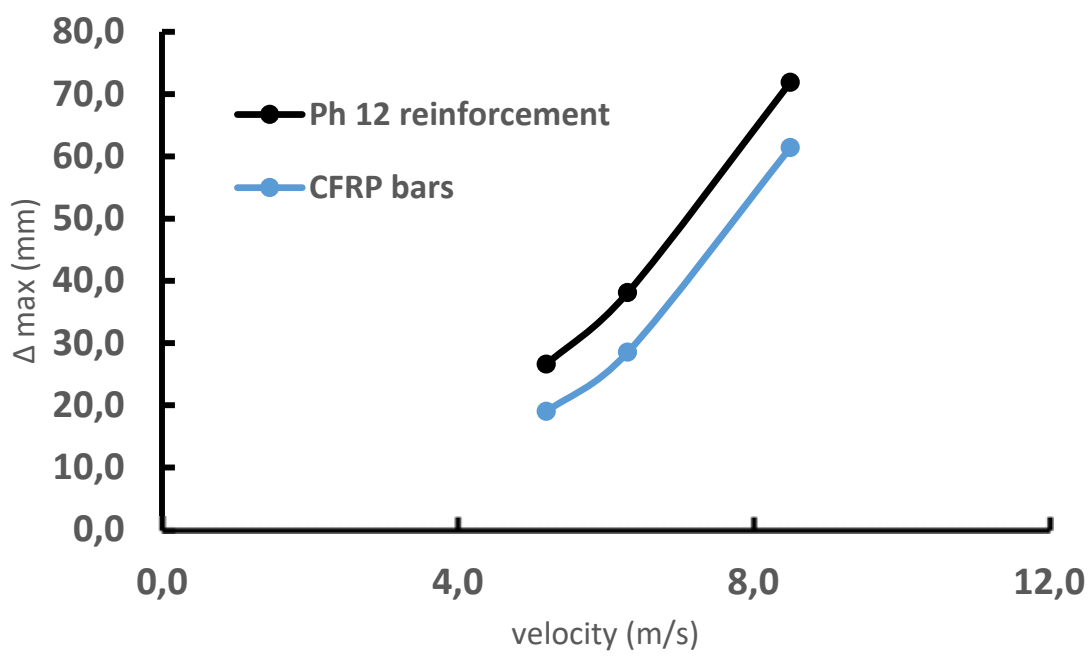

Figure 13: Comparing beams reinforcement models (maximum displacement vs. impact velocity)

Additional numerical models were generated to study the effects of important geometrical parameter related to the CFRP strengthen; thickness (th) of CFRP sheets. Fig. 14 shows the effects of (th) on the (D-t) histories, by comparing the response of three models, strengthened with th $=0.45$, strengthened with th $=0.9 \mathrm{~mm}$, and strengthened with th=1.8mm, for variable impact velocity (5.2 in Fig. 14 (a) and (d), 6.3 in Fig. 14 (b) and (e), and 8.5 in Fig. 14 (c) and (f) m/s) when using Ph 12 in Fig. 14 (a), (b) and (c), and CFRP bars in Fig. 14 (d), (e) and (f) for reinforcement beams. The deflection decreased by (7.9, $13.9) \%,(3.9,14.2) \%,(8.5,15.2) \%,(1.6,5.8) \%,(4.2,8.8) \%$ and $(7.5,9.9) \%$ as shown in Fig. 14 (a), (b), (c), (d), (e) and (f), respectively.

Because the effects of impact location on the behavior of CFRP-strengthened RC members under impact loads have not been investigated yet, they are included in the current parametric study. This factor was investigated by varying the impact position. The impactor's distance from the left side to half the beam's span length. values were chosen for $550 \mathrm{~mm}$ and 
$1100 \mathrm{~mm}$. Tab. 8 shows the crack patterns for the strengthened models with $0.45 \mathrm{~mm}$ thickness of CFRP layer under 6.3 $\mathrm{m} / \mathrm{s}$ impact velocity for both types of beams reinforced with Ph 12 and CFRP bars, with different values of impactor positions. Fig. 15 plots the displacement- time (D-t) histories to compare the displacement at midspan of the beam for variable impactor position.

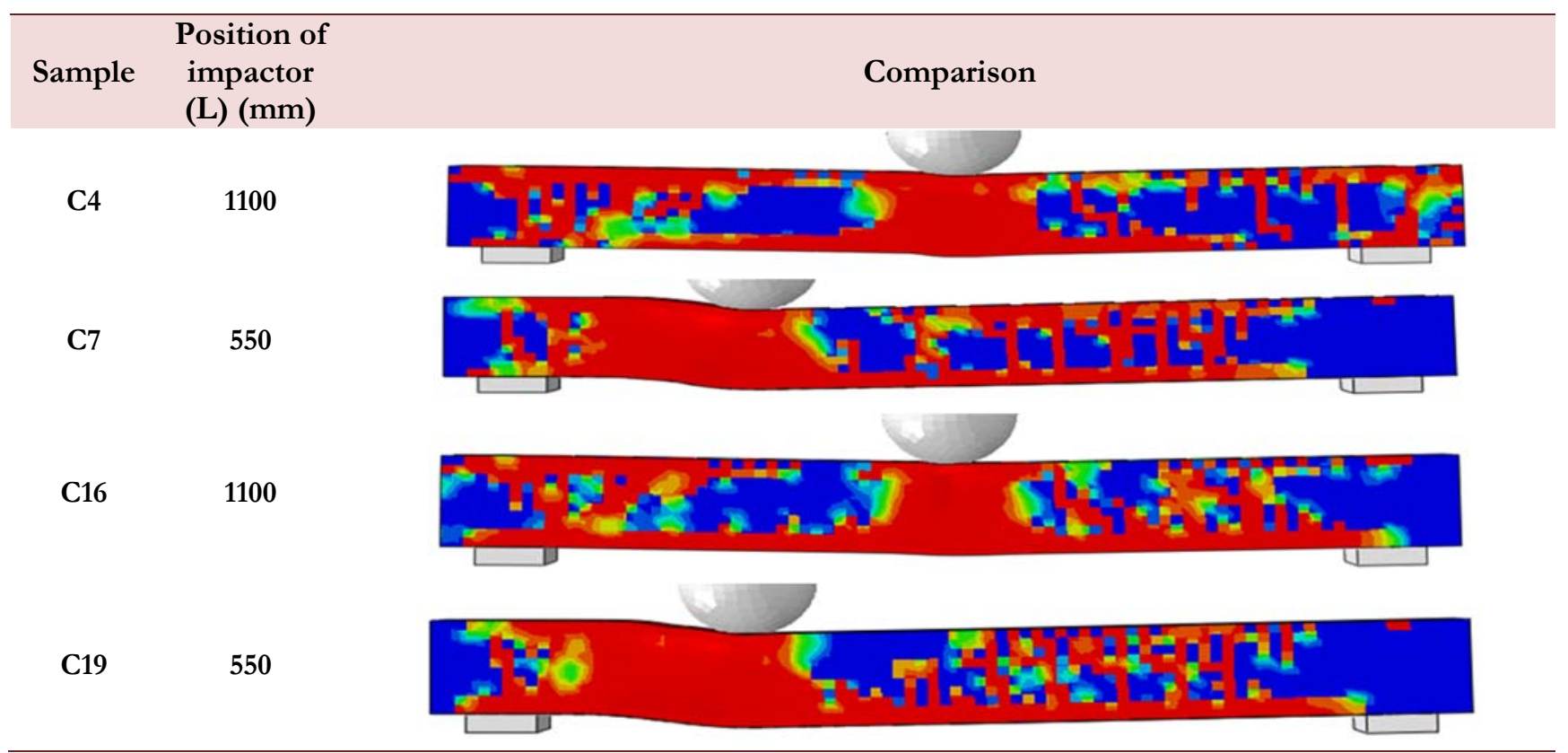

Table 8: Cracking patterns for different impact location.

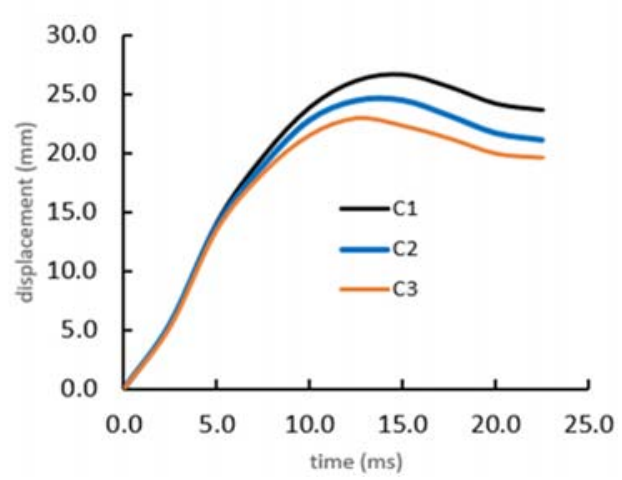

(a)

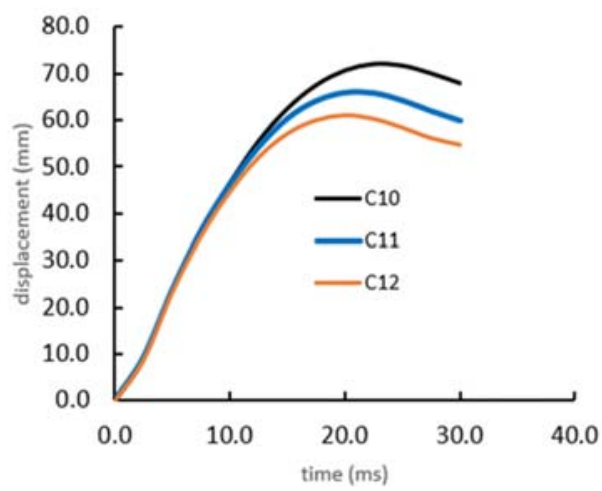

(c)

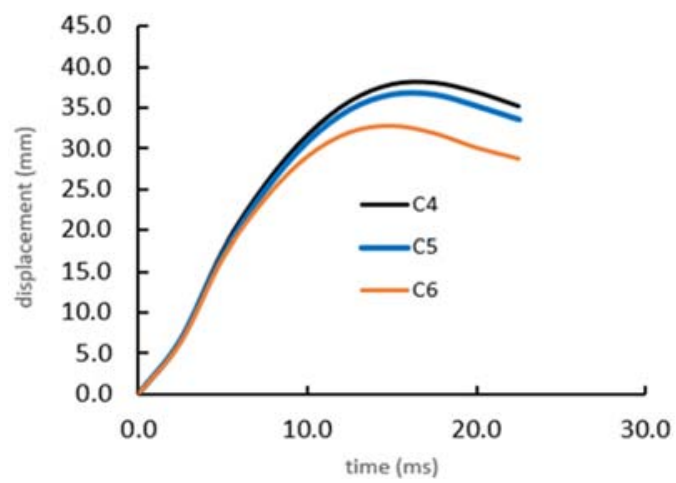

(b)

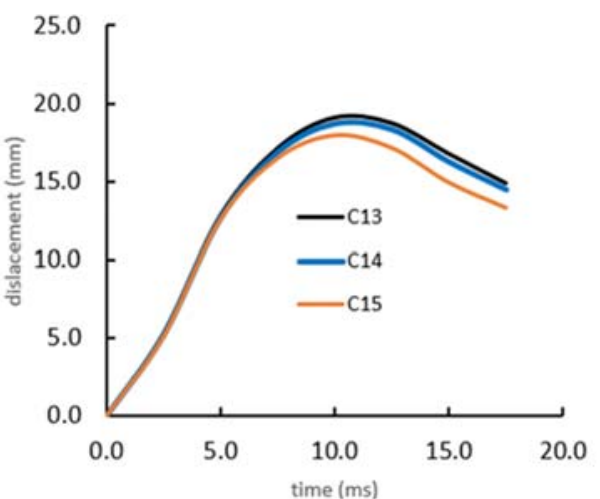

(d) 


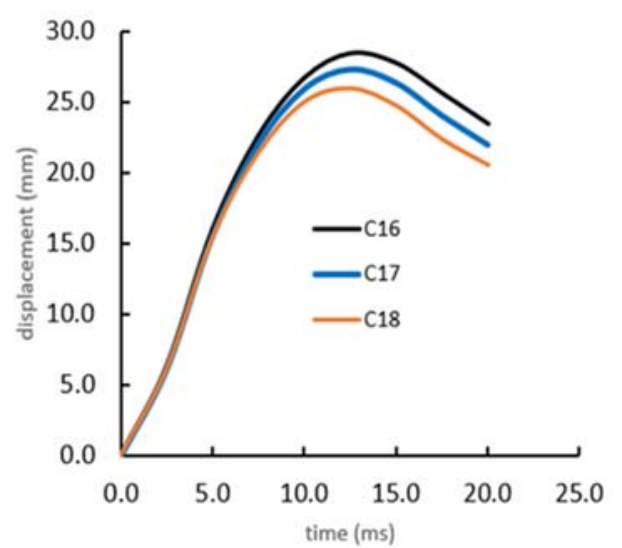

(e)

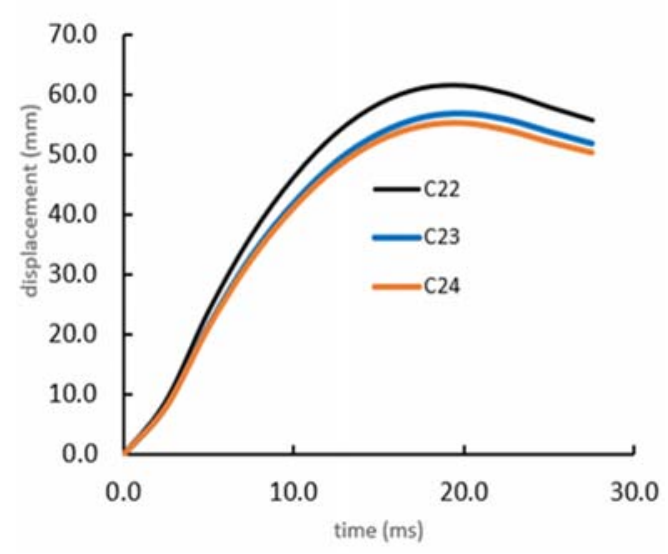

(f)

Figure 14: Effect of CFRP sheet thickness on displacement-time histories.

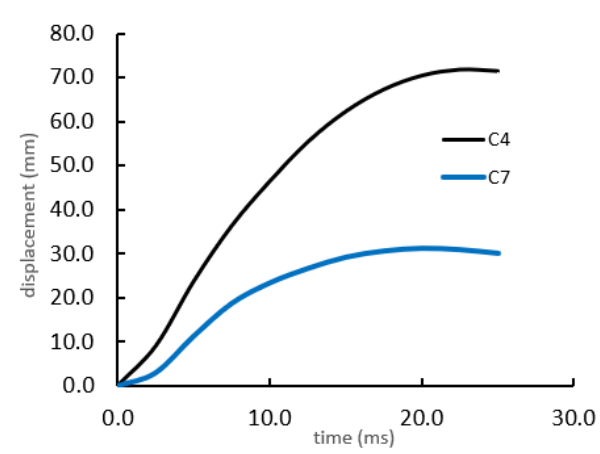

(a)

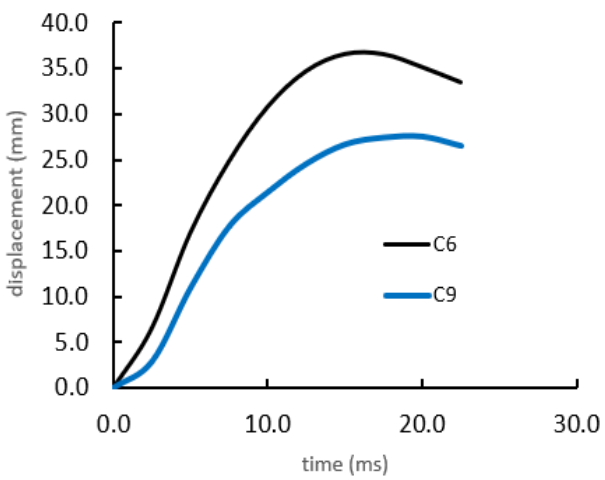

(c)

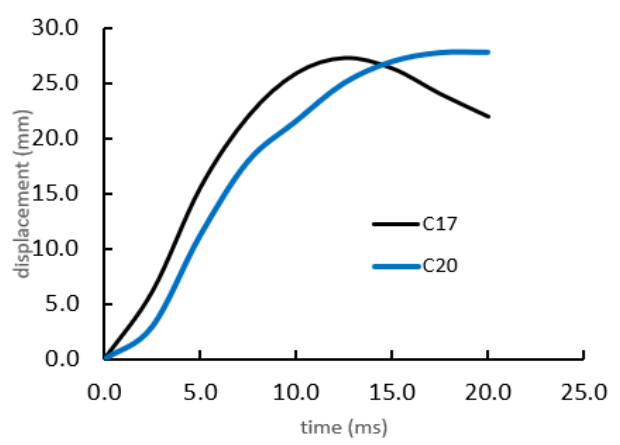

(e)

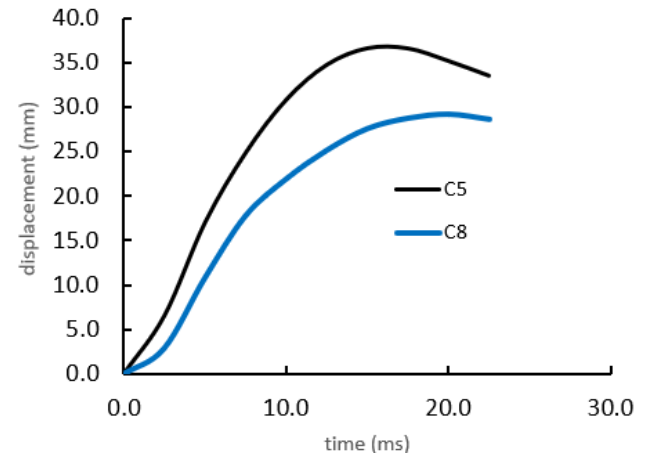

(b)

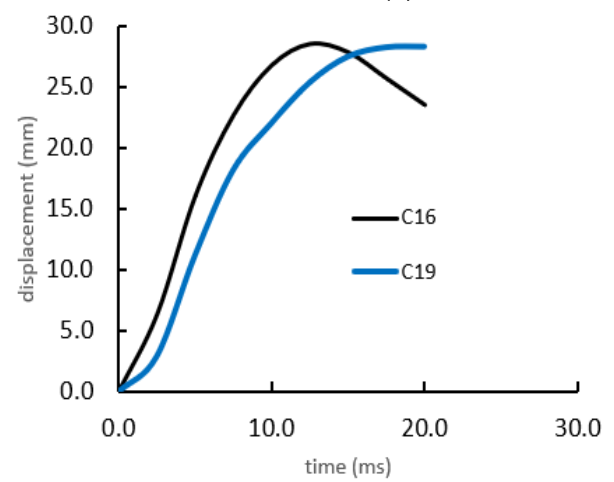

(d)

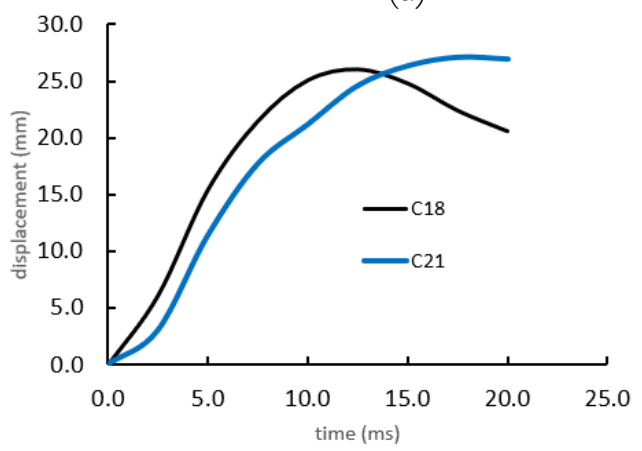

(f)

Figure 15: Effect of impact location on the displacement-time histories. 


\section{CONCLUSIONS AND RECOMMENDATIONS}

his study investigates numerically the behavior of RC beams strengthened with externally bonded CFRP sheets and subjected to impact load. The main parameters of the study were the reinforcing bars type and size, CFRP width, length, and thickness, impact velocity, and the position of the impactor. Based on the results obtained, the following conclusions can be drawn:

- The general behavior of the finite element models represented by time-deflection at midspan, time-load and failure mode curves showed good agreement with the test data from the full-scale beam tests.

- The finite element models showed a slight difference from the test data in both the linear and nonlinear ranges. This is most probably due to ignorance of the effect of concrete toughening mechanisms.

- The load-carrying capacity of the RC beams strengthened in flexural is higher than that of the control beam by $13.4 \%$.

- The failure modes obtained through the finite element models correspond well with the observed failure modes of the experimentally tested beams.

- Using CFRP bars as internal reinforcement reduced the mid-span deflection of RC beams by $29.1 \%$ compared to steel bars. Moreover, increasing the bar diameter decreased the mid-span deflection by 6.6 to $14.8 \%$.

- In the case of impact loadings, the load capacity of specimens reinforced with CFRP bars was much higher than that of steel.

- Increasing the length of the CFRP layer $(600 \mathrm{~mm}, 1200 \mathrm{~mm}$ and full beam length) decreased the midpoint deflection by $(2.1,7.3 \%)$, and impact forces by $(1.7,4.3 \%)$ for beams (B3, B4 and B5).

- Increasing the CFRP layer width from $75 \mathrm{~mm}$ to $150 \mathrm{~mm}$ decreased the midpoint deflection of RC beams subjected to impact loading by $6.5 \%$ for beams (B4 and B7).

- Increasing impact velocity from 5.2 to 6.3 then $8.5 \mathrm{~m} / \mathrm{s}$ increased the deflection of RC beams by $26.6,38.1$ and $71.9 \mathrm{~mm}$, respectively.

- The displacement decreased from 7.9 to $13.9 \%$ for beams (C1, C2 and C3) due to increasing the thickness of the CFRP strengthening layer (0.45, 0.9 and $1.8 \mathrm{~mm})$.

- The change of impactor position from $550 \mathrm{~mm}$ to $1100 \mathrm{~mm}$ concerning the left side to half beam length increased the displacement values from $31.2 \mathrm{~mm}$ to $71.9 \mathrm{~mm}$ and changed the failure modes of tested beams.

\section{REFERENCES}

[1] Bakis, C.E., Bank, L.C., Brown, V.L., Cosenza, E., Davalos, J.F., Lesko, J.J., Machida, A., Rizkalla, S.H., Triantafillou, T.C. (2003). Fiber-Reinforced Polymer Composites for Construction - State-of-the-Art Review, Perspect. Civ. Eng. Commem. 150th Anniv. Am. Soc. Civ. Eng., 6(May), pp. 369-383, DOI: 10.1061/(asce)1090-0268(2002)6:2(73).

[2] Wight, J.K., Barth, F.G., Becker, R.J., Bondy, K.B., Breen, J.E., Cagley, J.R., Collins, M.P., Corley, W.G., Dolan, C.W., Fiorato, A.E., French, C.E., Garcia, L.E., Griffis, L.G., Gustafson, D.P., Harman, D.K., Harris, J.R., Hawkins, N.M., Holland, T.C., Iverson, P.J., Jirsa, J.O., Kelly, D.J., Klein, G.J., Kopczynski, C.S., Martin, L.D., Mast, R.F., Mccabe, S.L., Mccall, W.C., Moehle, J.P., Murray, M.A., Ramirez, J.A., Stark, R., Tolles, E.M., Wood, S.L., Aschheim, M.A. (2005). ACI Committee 318,"Building Code Requirements For Structural Concrete (ACI 318-05) and commentary (ACI 318R05)", Am. Concr. Institute, Farmingt. Hills, MI, 2003, pp. 430.

[3] Emara, M., Barris, C., Baena, M., Torres, L., Barros, J. (2018). Bond behavior of NSM CFRP laminates in concrete under sustained loading, Constr. Build. Mater., 177, pp. 237-246, DOI: 10.1016/j.conbuildmat.2018.05.050.

[4] Kadhim, M.M.A. (2012). Effect of CFRP Sheet Length on the Behavior of HSC Continuous Beam, J. Thermoplast. Compos. Mater., 25(1), pp. 33-44, DOI: 10.1177/0892705711401847.

[5] Quantrill, R.J., Hollaway, L.C., Thorne, A.M. (1996). Experimental and analytical investigation of FRP strengthened beam response: Part I, Mag. Concr. Res., 48(4), pp. 331-42, DOI: 10.1680/MACR.1996.48.177.331.

[6] Kadhim, M.M.A.;Mohammed, M. J.; Abid, A.J. (2012). Effect of Prestressed CFRP Plate Location on Behavior of RC Beam Strengthened with Prestressed CFRP Plate, Babylon University, 20(1), pp. 105-113, Available at: https://www.researchgate.net/publication/333056468_Effect_of_Prestressed_CFRP_Plate_Location_on_Behavior_ of_RC_Beam_Strengthened_with_Prestressed_CFRP_Plate.

[7] Fujikake, K., Li, B., Soeun, S. (2009). Impact Response of Reinforced Concrete Beam and Its Analytical Evaluation, J. 
Struct. Eng., 135(8), pp. 938-950, DOI: 10.1061/(asce)st.1943-541x.0000039.

[8] Pham, T.M., Hao, H. (2016). Impact Behavior of FRP-Strengthened RC Beams without Stirrups, J. Compos. Constr., 20(4), pp. 04016011, DOI: 10.1061/(asce)cc.1943-5614.0000671.

[9] Soudki, K., Alkhrdaji, T. (2005). Guide for the Design and Construction of Externally Bonded FRP Systems for Strengthening Concrete Structures (ACI 440.2R-02), Proc. Struct. Congr. Expo., pp. 1627-1633, DOI: $10.1061 / 40753(171) 159$.

[10] Kantar, E., Erdem, R. T., Anil, Ö. (2011). Nonlinear finite element analysis of impact behavior of concrete beam, Mathematical and Computational Applications, 16(1), pp. 183-193.

[11] Erki, M.A., Meier, U. (1999). Impact Loading of Concrete Beams Externally Strengthened with CFRP Laminates, J. Compos. Constr., 3(3), pp. 117-124, DOI: 10.1061/(ASCE)1090-0268(1999)3:3(117).

[12] Tang, T., Saadatmanesh, H. (2003). Behavior of Concrete Beams Strengthened with Fiber-Reinforced Polymer Laminates under Impact Loading, J. Compos. Constr., 7(3), pp. 209-218, DOI: $10.1061 /$ (asce)1090-0268(2003)7:3(209).

[13] Esfahani, M.R., Kianoush, M.R., Tajari, A.R. (2007). Flexural behaviour of reinforced concrete beams strengthened by CFRP sheets, Eng. Struct., 29(10), pp. 2428-2444, DOI: 10.1016/J.ENGSTRUCT.2006.12.008.

[14] Soleimani, S., Banthia, N., Mindess, S. (2007). Behavior of RC beams under impact loading: some new findings. In proceedings of the 6th Int. conference on fracture mechanics of concrete and concrete structures, Catania, Italy.

[15] Watstein, D. (1953). Effect of Straining Rate on the Compressive Strength and Elastic Properties of Concrete, J. Proc., 49(4), pp. 729-44, DOI: $10.14359 / 11850$.

[16] Goldston, M., Remennikov, A., Sheikh, M.N. (2016). Experimental investigation of the behaviour of concrete beams reinforced with GFRP bars under static and impact loading, Eng. Struct., 113, pp. 220-232, DOI: 10.1016/J.ENGSTRUCT.2016.01.044.

[17] Khalighi, Y. (2009). A study of bond between fibre reinforced polymer and concrete under quasi static and impact loading, PhD Dissertation, University of British Columbia Library, DOI: 10.14288/1.0063162.

[18] Al-Farttoosi, M. (2016). Impact Behaviour of Reinforced Concrete Beams Strengthened or Repaired with Carbon Fibre Reinforced Polymer (CFRP), PhD Dissertation, University of Plymouth.

[19] Pham, T.M., Hao, H. (2017). Behavior of fiber-reinforced polymer-strengthened reinforced concrete beams under static and impact loads, Int. J. Prot. Struct., 8(1), pp. 3-24, DOI: 10.1177/2041419616658730.

[20] AbuLebdeh, T.M., Voyiadjis, G.Z. (1993). PlasticityDamage Model for Concrete under Cyclic Multiaxial Loading, J. Eng. Mech., 119(7), pp. 1465-1484, DOI: 10.1061/(ASCE)0733-9399(1993)119:7(1465).

[21]Jankowiak, T., and, Lodygowski, T. (2005). Identification of parameters of concrete damage plasticity constitutive model, Foundations of civil and environmental engineering, 6(1), pp. 53-69.

[22] Voyiadjis, G.Z., Abu-Lebdeh, T.M. (1994). Plasticity model for concrete using the bounding surface concept, Int. J. Plast., 10(1), pp. 1-21, DOI: 10.1016/0749-6419(94)90051-5.

[23] Emara, M., Hamoda, A. (2019). Numerical Modeling of Time-Displacement Response ofRC Slab Subjected to Impact Loading ., 16(5), pp. 11-20, DOI: 10.9790/1684-1605031120www.iosrjournals.org.

[24] Hashin, Z. (1981). Fatigue Failure Criteria for Unidirectional Fiber Composites, J. Appl. Mech., 48(4), pp. 846-852, DOI: $10.1115 / 1.3157744$.

[25] Dauphin, J.-C., Jean-Christophe. (2016). Guide du chercheur américaniste à Brown University, Providence, Rhode Island, USA, Http://Journals.Openedition.Org/Nuevomundo, , DOI: 10.4000/NUEVOMUNDO.70083.

[26] Hashin, Z. (1980). Failure Criteria for Unidirectional Fiber Composites, J. Appl. Mech., 47(2), pp. 329-334, DOI: $10.1115 / 1.3153664$

[27] Soleimani, S., Sayyar, R. S. (2019). Analytical study of reinforced concrete beams tested under quasi-static and impact loadings, J. Appl. Sci., 9(14), pp. 2838, DOI: 10.3390/app9142838.

[28] Al-Zubaidy, H., Al-Mahaidi, R., Zhao, X.L. (2013). Finite element modelling of CFRP/steel double strap joints subjected to dynamic tensile loadings, Compos. Struct., 99, pp. 48-61, DOI: 10.1016/J.COMPSTRUCT.2012.12.003.

[29] Kadhim, M., Wu, Z. J., Cunningham, L. (2016). FE modelling of CFRP strengthened steel members under impact loads, In Proceedings of the 24th UK Conference of the Association for Computional Mechanics in Engineering, UK.

[30] Kadhim, M.M.A., Wu, Z., Cunningham, L.S. (2018). Experimental study of CFRP strengthened steel columns subject to lateral impact loads, Compos. Struct., 185, pp. 94-104, DOI: 10.1016/J.COMPSTRUCT.2017.10.089.

[31] Zeinoddini, M., Harding, J.E., Parke, G.A.R. (2008). Axially pre-loaded steel tubes subjected to lateral impacts (a numerical simulation), Int. J. Impact Eng., 35(11), pp. 1267-1279, DOI: 10.1016/J.IJIMPENG.2007.08.002.

[32] Genikomsou, A.S., Polak, M.A. (2017). Finite Element Analysis of RC Flat Slabs with Different Amount and Placement of Shear Bolts, Spec. Publ., 321, pp. 6.1-6.20. 